\title{
Systemic Statistical Optimization of Astaxanthin Inducing Methods in Haematococcus pluvialis cells
}

\section{Statistical Optimization of Astaxanthin Production in Haematococcus}

\author{
Sun-Hyoung Kim', Sung Eun Jeong', Seong-Joo Hong', Choul-Gyun Lee ${ }^{1 *}$ \\ ${ }^{1}$ National Marine Bioenergy Research Center \& Department of Biological Engineering, Inha University, Incheon 402-751, Republic of Korea \\ (2014년 6월 30일 접수, 2014년 7월 31일 수정, 2014년 7월 31일 채택)
}

\begin{abstract}
The production of astaxanthin in the microalga Haematococcus pluvialis has been investigated using a sequential methodology based on the application of two types of statistical designs. The employed preliminary experiment was a fractional factorial design $2^{6}$ in which the factors studied were: excessive irradiance and nitrate starvation, phosphate deficiency, acetate supplementation, salt stress, and elevated temperature. The experimental results indicate that the amount of astaxanthin accumulation in the cells can be enhanced by excessive irradiance and nitrate starvation whereas the other factors tested did not yield any enhancement. In the subsequent experiment, a central composite design was applied with four variables, light intensity, nitrate, phosphate, and acetate, at five levels each. The optimal conditions for the highest astaxanthin production were found to be $1040 \mu \mathrm{E} /\left(\mathrm{m}^{2} \cdot \mathrm{s}\right)$ light intensity, $0.04 \mathrm{~g} / \mathrm{L}$ nitrate, $0.31 \mathrm{~g} / \mathrm{L}$ phosphate, $0.05 \mathrm{~g} / \mathrm{L}$ acetate concentration.
\end{abstract}

Keywords : Haematococcus pluvialis, astaxanthin, statistical optimization of astaxanthin inducing methods, fractional factorial design, central composite design

\section{Introduction}

Astaxanthin (3,3'-dihydroxy- $\beta, \beta$-carotene-4,4'-dione) occurs as a pinkish ketocarotenoid in many aquatic animals including salmon, trout, shrimp, red sea beam, ornamental fish, and many crustaceans. Industrial aquacultures of sea food depend heavily on an inexpensive source of astaxanthin as a feed supplement [17]. Additionally, astaxanthin surpasses the antioxidant activity of other carotenoids such as $\beta$-carotene, zeaxanthin, and canthaxanthin, and even vitamin E [32]. The pharmaceutical and cosmetic industries are increasingly becoming interested in astaxanthin since it can, for instance, protect against the damaging effects of ultraviolet radiation and chemically induced cancers and also enhance the immune system [22]. Because of the high market price of synthetic astaxanthin, there have been several efforts to use microorganisms such as the green algae Haematococcus, Chlorococcum sp., and Chlorella vulgaris and the heterobasidiomycete yeast Xanthophyllomyces dendrorhous (anamorph: Phaffia rhodozyma) as a natural source of the product $[15,24]$. Haematococcus pluvialis is considered the most promising among these, as it accumulates the $3 S$, 3'S-isomer of astaxanthin, mostly in its mono- or di-ester form, as the main part of so-called secondary carotenoids (SC) in cytoplasmic lipid vesicles. Haematococcus shows the highest accumulation level known in astaxanthin-producing

\footnotetext{
* Corresponding author

Phone: +82-32-872-7518 Fax: +82-32-873-7518

E-mail: leecg@inha.ac.kr
}

This is an open-access journal distributed under the terms of the Creative Commons Attribution Non-Commercial License

(http://creativecommons.org/licenses/bync/3.0) 
organisms. However, the accumulation of high levels of astaxanthin in Haematococcus has accompanying drawbacks. Low growth rate, thick cell walls, and low cell density have blocked commercial use of the best producer of astaxanthin. However, it is expected that advanced algal biotechnology will help break these barriers $[2,20]$.

Haematococcus accumulates astaxanthin during transformation to the aplanospore stage as a response to stress conditions. The importance of the different factors inducing astaxanthin accumulation is not clear. It is known that external stress is important in the induction of astaxanthin accumulation.

The effect of light is likely the most important consideration in astaxanthin accumulation. Two properties of light energy are important for astaxanthin accumulation: intensity and spectral quality. Light intensity had a significant effect on cell growth and level of astaxanthin accumulation in cells [13]. The optimum photon flux density corresponding to the maximum level of algal biomass production was $60 \mathrm{~m} \mu \mathrm{E} /\left(\mathrm{m}^{2} \cdot \mathrm{s}\right)$ [9]. High light intensity caused relatively large quantities of astaxanthin to be accumulated in the cells of Haematococcus [6,21]. Spectral quality is defined by the absorption spectrum for chlorophyll and other photosynthetically active pigments (astaxanthin and carotenoids). The supplement of specified wavelength light is expected to enhance astaxanthin production $[13,22]$.

The synthesis of secondary carotenoids in macroalgae appears to be dependent upon a large number of environmental factors. Of particular importance is depletion of the nutrient source in the medium [7,8]. Another report showed that $\mathrm{N}$-deficiency [21] induced astaxanthin formation and $\mathrm{C} / \mathrm{N}$ balance[12] in the medium determined the degree of carotene formation [4]. Phosphate starvation was reported previously to act as a trigger for the accumulation of astaxanthin [10]. N, $\mathrm{C}$, and $\mathrm{P}$ are essential nutrients that determine the rate of synthesis and final concentration of astaxanthin. Metal ions, oxidative stress, and salt stress stimulate the formation of astaxanthin in this alga $[1,4,10,25]$. The ferrous form of iron is known to give rise to free radical formation via the
Fenton reaction, and free radicals may play a role in astaxanthin formation. Active oxygen species $\left(\mathrm{O}_{2}, \mathrm{H}_{2} \mathrm{O}_{2}\right.$, peroxy radical) also enhance the formation of astaxanthin [14]. In addition, astaxanthin formation is significantly affected by elevated temperature and $\mathrm{pH}$ [27].

In the present work, statistical methods are used to optimize the conditions of astaxanthin production in Haematococcus cells. The first design (fractional factorial design) analyzes the main factors that may influence astaxanthin production. The second design (central composite design) determines the optimum conditions for astaxanthin production.

\section{Materials and Methods}

\section{Microorganism and Culture Conditions}

The green microalga Haematococcus pluvialis (=H.lacustris, UTEX 16) was obtained from the University of Texas Culture Collection (Austin, TX, USA). The culture medium used was fortified BBM (Bolds Basal Medium) [26,28]. Bold Basal Medium consists of six macro-nutrients (in g/L): $\mathrm{NaNO}_{3}$, 0.246; $\mathrm{CaCl}_{2} 2 \mathrm{H}_{2} \mathrm{O}, \quad 0.025 ; \quad \mathrm{MgSO}_{4} \cdot 7 \mathrm{H}_{2} \mathrm{O}, \quad 0.074$; $\mathrm{K}_{2} \mathrm{HPO}_{4}, 0.075 ; \mathrm{KH}_{2} \mathrm{PO}_{4}, 0.175 ; \mathrm{NaCl}, 0.251$. The micronutrients were supplied by adding $1 \mathrm{~mL}$ of trace element stock solution (per liter, $50 \mathrm{~g}$ EDTA, 30.8 g KOH, 4.98 g $\mathrm{FeSO}_{4} \cdot 7 \mathrm{H}_{2} \mathrm{O}, 0.98$ g $\mathrm{H}_{2} \mathrm{SO}_{4}$, 11.13 g $\mathrm{H}_{3} \mathrm{BO}_{3}, \quad 8.83$ g $\quad \mathrm{ZnSO}_{4} 7 \mathrm{H}_{2} \mathrm{O}, \quad 1.44 \mathrm{~g}$ $\mathrm{MnCl}_{2} \cdot 4 \mathrm{H}_{2} \mathrm{O}, 0.71$ g $\mathrm{MoO}_{3}, 1.57$ g $\mathrm{CuSO}_{4} \cdot 5 \mathrm{H}_{2} \mathrm{O}$, $\left.0.49 \mathrm{~g} \mathrm{Co}\left(\mathrm{NO}_{3}\right)_{2} \cdot 6 \mathrm{H}_{2} \mathrm{O}\right)$ to $1 \mathrm{~L}$ of macronutrient solution. The FBBM contained four times the concentration of $\mathrm{MoO}_{3}$ and $0.00049 \mathrm{~g} / \mathrm{L}$ $\mathrm{Na}_{2} \mathrm{MoO}_{4} \cdot 2 \mathrm{H}_{2} \mathrm{O}$ was added. The medium was autoclaved at $121^{\circ} \mathrm{C}$ for $15 \mathrm{~min}$ and adjusted to $\mathrm{pH}$ 6.5. A fresh medium with concentrated nitrate was fed whenever the nitrate level was lower than $10 \%$ of the initial level.

Subcultures were generally prepared by suspending a single colony from a master plate in a $250 \mathrm{~mL}$ Erlenmeyer flask containing $100 \mathrm{~mL}$ of FBBM. The seed culture flask was cultured for 7 days in an illuminated shaking incubator (model VS-8480SF, VISION SCINTIFIC Co., LTD., Korea) at a constant light intensity of $60 \pm 5 \mu \mathrm{E} /\left(\mathrm{m}^{2} \cdot \mathrm{s}\right)$ at $175 \mathrm{rpm}$. Fractional factorial design (FFD) and central composite design (CCD) experiments were carried out in a $250 \mathrm{~mL}$ Erlenmeyer flask, using 
$100 \mathrm{~mL}$ as a working volume. Experiments were inoculated at a cell density of $3 \times 10^{5}$ cell $/ \mathrm{mL}$. The flasks were cultured for 7 days on a shaking incubator at $175 \mathrm{rpm}$ with a cooling system. Light sources were fluorescent lamps (FL18D, OSRAM, Korea) and $500 \mathrm{~W}$ linear tungsten-halogen lamps (500W, OSRAM, Korea).

\section{Measurement of cell concentration and dry cell weight}

Cell concentration and cell size distribution were measured by a computer-controlled Coulter Counter (model Z2, Coulter Electronics, Inc., Miami, FL, USA) [22]. To measure astaxanthin productivity, dry cell weight was measured after each experiment run.

\section{Analysis of Pigment}

Astaxanthin concentration was calculated by a calibration curve obtained for synthetic astaxanthin (product number A9335, Sigma Chemical Co., St Louis, MO, USA) as a standard. For astaxanthin concentration less than $10 \mathrm{mg} / \mathrm{L}$, the following calibration was used: astaxanthin concentration $(\mathrm{mg} / \mathrm{L})=0.0045 \times \mathrm{OD}_{475}$.

More quantitative and qualitative measurements of astaxanthin were conducted via HPLC (Younglin Instrument Co., Anyang, Korea) with two M930D pumps and a M730D photodiode array (PDA) detector. The astaxanthin was separated and analyzed $\left(20 \mathrm{~L}\right.$ aliquots) using a reversed-phase $\mathrm{C}_{18}$ column $(300 \times 3.9 \mathrm{~mm} ; 5 \mathrm{~m}$, Waters Co., Milford, MA, USA) at ambient temperature. The mobile phase consisted of hexane $(82 \%)$ and acetone $(18 \%)$. The flow $\mathrm{r}$ ate was set at $1.2 \mathrm{~mL} / \mathrm{min}$. The detection wavelength of the PDA detector was set at 250 and $700 \mathrm{~nm}$ and the chromatographic peaks were measured at a wavelength of $474 \mathrm{~nm}$ to facilitate the detection of astaxanthin [16,31]. For accurate quantification of esterified astaxanthin by HPLC, a hydrolysis method has been developed [30]. Esterified astaxanthin was hydrolyzed by an enzymatic procedure to yield free astaxanthin. $600 \mathrm{~L}$ of 3.4 units $/ \mathrm{mL}$ enzyme (cholesterol esterase from Pseudomonas flourescens (Sigma C-9281)) stock solution in a prepared buffer of $0.05 \mathrm{M}$ Tris- $\mathrm{HCl}$ $\mathrm{pH} 7.0$ was added to a $3 \mathrm{~mL}$ mixture of the pigment extract solution and $2 \mathrm{~mL}$ of $0.05 \mathrm{M}$ Tris- $\mathrm{HCl} \mathrm{pH} \mathrm{7.0.} \mathrm{The} \mathrm{mixture} \mathrm{reacted} \mathrm{in} 37^{\circ} \mathrm{C}$ water bath for 45 minutes with mixing. $1.0 \mathrm{~g}$ $\mathrm{Na}_{2} \mathrm{SO}_{4} 10 \mathrm{H}_{2} \mathrm{O}$ and $4 \mathrm{~mL}$ of petroleum ether were added and the resultant solution was centrifuged for 3 minutes at 3,500 rpm. The mixture was evaporated and re-dissolved into $3 \mathrm{~mL}$ of mobile phase for HPLC analysis [16].

\section{Optimization Procedure}

\section{Identification of important factors on astaxanthin production}

A factorial design is employed to identify the most important nutritional and physical parameters and determine the effect of these parameters on astaxanthin production. Six variables (light intensity, nitrate $\left(\mathrm{NaNO}_{3}\right)$, phosphate $\left(\mathrm{K}_{2} \mathrm{HPO}_{4}+\mathrm{KH}_{2} \mathrm{PO}_{4}\right)$, acetate $\left(\mathrm{CH}_{3} \mathrm{COONa}\right)+\mathrm{pH}$, salt $(\mathrm{NaCl})$, temperature $)$ were evaluated with 0 center points in 16 runs of a resolution III design. A $2_{I I I}^{6-3}$ fractional factorial design using the following design generators: $D= \pm A B, \quad E= \pm A C, \quad F= \pm B C$. Low (-) level was the original culture condition for Haematococcus, as discussed below, and high $(+)$ level denotes the inducing culture condition, as presented in Table 1.

Table 1. Variables screened in FFD and real values for the two levels used in FFD

\begin{tabular}{lcccc}
\hline & Variables & Unit & $\begin{array}{c}\text { Low level } \\
(\mathbf{- 1})\end{array}$ & $\begin{array}{c}\text { High level } \\
(+\mathbf{1})\end{array}$ \\
\hline $\mathrm{A}$ & Light & $\mu \mathrm{E} /\left(\mathrm{m}^{2} \cdot \mathrm{s}\right)$ & 40 & 200 \\
$\mathrm{~B}$ & Nitrate & $\mathrm{g} / \mathrm{L}$ & 0.246 & 0 \\
$\mathrm{C}$ & Phosphate & $\mathrm{g} / \mathrm{L}$ & 0.25 & 0 \\
$\mathrm{D}$ & Acetate $+\mathrm{pH}$ & $\mathrm{g} / \mathrm{L}$ & $0, \mathrm{pH}=6.5$ & $0.1, \mathrm{pH}=7.5$ \\
$\mathrm{E}$ & Salt & $\mathrm{g} / \mathrm{L}$ & 0.025 & 0.225 \\
$\mathrm{~F}$ & Temperature & ${ }^{\circ} \mathrm{C}$ & 25 & 30 \\
\hline
\end{tabular}

For the astaxanthin production, astaxanthin concentration per fresh weight was selected as the response, and can be calculated using equation (3) [11].

$$
y=\beta_{0}+\sum_{i}^{k} \beta_{i} x_{i}+\sum \sum_{i>j} \beta_{i j} x_{i} x_{j}+\varepsilon
$$

where $y$ is the predicted response, $\beta_{i}$ is the coefficient of the equation, $\beta_{0}$ is the intercept of the plane, $x_{i}$ and $x_{j}$ are coded levels of variables, and $\varepsilon$ is the error term. The effects of each variable were determined by the software MINITAP (V 13.20, MINITAP Inc.). The 
$i^{\text {th }}$ effect is estimated as (4) $[19,29]$.

$$
\ell_{i}=\frac{2\left(\text { Contrast }_{i}\right)}{N}=\frac{\text { Contrast }_{i}}{(N / 2)}
$$

where Contrast $_{i}$ can be calculated in accordance with the plus and minus signs in column $i$ and $N=2^{k-p}$ is the total number of observations.

Optimization of important factors on astaxanthin production

The next step in the optimization procedure is the determination of the optimum level of each of the previously identified independent variables [18]. A central composite design (CCD) is an efficient design that is considered ideal for sequential experimentation. It can handle a reasonable amount of information to test lack of fit and does not involve an unusually large number of design points. We specified the range on the design variables and performed experiments within these regions, as it was thought that optimal conditions might exist within the restricted regions and the design is known to be useful for any number of design variables.

Table 2. Real values of independent variables in CCD

\begin{tabular}{ccccc}
\hline & $\begin{array}{c}\text { Light Intensity } \\
\left(\mu \mathbf{E} /\left(\mathbf{m}^{2} \cdot \mathbf{s}\right)\right)\end{array}$ & $\begin{array}{c}\text { Nitrate } \\
(\mathbf{g} / \mathbf{L})\end{array}$ & $\begin{array}{c}\text { Phosphate } \\
(\mathbf{g} / \mathbf{L})\end{array}$ & $\begin{array}{c}\text { Acetate } \\
(\mathbf{g} / \mathbf{L})\end{array}$ \\
\hline 2 & 1040 & 0.492 & 0.5 & 0.4 \\
1 & 790 & 0.369 & 0.375 & 0.3 \\
0 & 540 & 0.246 & 0.25 & 0.2 \\
-1 & 290 & 0.123 & 0.125 & 0.1 \\
-2 & 40 & 0 & 0 & 0 \\
\hline
\end{tabular}

As shown in Table 3, the CCD consisted of $2^{4}$ factorial with 30 runs, 4 center points, and 10 axial points. Four variables (light intensity, nitrate $\left(\mathrm{NaNO}_{3}\right)$, phosphate $\left(\mathrm{K}_{2} \mathrm{HPO}_{4}+\mathrm{KH}_{2} \mathrm{PO}_{4}\right)$, acetate $\left.\left(\mathrm{CH}_{3} \mathrm{COONa}\right)+\mathrm{pH}\right)$ were at five levels and true values of the variables are given in Table2.

According to this design, the total number of treatment combinations is $2^{k}+2 K+n_{0}$, where $k$ is the number of independent variables and $n_{0}$ is the number of repetitions of the experiment at the center point. For statistical calculations, the variables $X_{i}$ were coded as $x_{i}$ according to the following equation.

$$
x_{i}=\left(X_{i}-X_{0}\right) / \delta X
$$

Table 3. Variables of CCD shown in coded level

\begin{tabular}{ccccccc}
\hline Pattern & $\mathbf{B l o c k}_{\mathbf{k}}$ & $\mathbf{X}_{\mathbf{1}}^{\mathbf{a}}$ & $\mathbf{X}_{\mathbf{2}}^{\mathbf{b}}$ & $\mathbf{X}_{\mathbf{3}}^{\mathbf{c}}$ & $\mathbf{X}_{\mathbf{4}}^{\mathbf{d}}$ & Comment \\
\hline---+ & 1 & -1 & -1 & -1 & +1 & Full Factorial \\
--+- & 1 & -1 & -1 & +1 & -1 & Full Factorial \\
-+-- & 1 & -1 & +1 & -1 & -1 & Full Factorial \\
-+++ & 1 & -1 & +1 & +1 & +1 & Full Factorial \\
+--- & 1 & +1 & -1 & -1 & -1 & Full Factorial \\
+-++ & 1 & +1 & -1 & +1 & +1 & Full Factorial \\
++-+ & 1 & +1 & +1 & -1 & +1 & Full Factorial \\
+++- & 1 & +1 & +1 & +1 & -1 & Full Factorial \\
0000 & 1 & 0 & 0 & 0 & 0 & Center-Full \\
& & & & & & Factorial \\
0000 & 1 & 0 & 0 & 0 & 0 & Fanter-Full \\
--- & 2 & -1 & -1 & -1 & -1 & Full Factorial \\
--++ & 2 & -1 & -1 & +1 & +1 & Full Factorial \\
-+-+ & 2 & -1 & +1 & -1 & +1 & Full Factorial \\
-++- & 2 & -1 & +1 & +1 & -1 & Full Factorial \\
+--+ & 2 & +1 & -1 & -1 & +1 & Full Factorial \\
+-+- & 2 & +1 & -1 & +1 & -1 & Full Factorial \\
++-- & 2 & +1 & +1 & -1 & -1 & Full Factorial \\
++++ & 2 & +1 & +1 & +1 & +1 & Full Factorial \\
0000 & 2 & 0 & 0 & 0 & 0 & Center-Full \\
0000 & 2 & 0 & 0 & 0 & 0 & Factorial \\
+000 & 3 & -2 & 0 & 0 & 0 & Factorial \\
+000 & 3 & +2 & 0 & 0 & 0 & Axial \\
+000 & 3 & +2 & 0 & 0 & 0 & Axial \\
$0-00$ & 3 & 0 & -2 & 0 & 0 & Axial \\
$0+00$ & 3 & 0 & +2 & 0 & 0 & Axial \\
$00-0$ & 3 & 0 & 0 & -2 & 0 & Axial \\
$00+0$ & 3 & 0 & 0 & +2 & 0 & Axial \\
$000-$ & 3 & 0 & 0 & 0 & -2 & Axial \\
$000+$ & 3 & 0 & 0 & 0 & +2 & Axial \\
0000 & 3 & 0 & 0 & 0 & 0 & Center-Axial \\
\hline+ & & & & &
\end{tabular}

${ }^{\mathrm{a}}$ Light intensity, ${ }^{\mathrm{b}}$ Nitrate, ${ }^{\mathrm{c}}$ Phosphate, ${ }^{\mathrm{d}}$ Acetate.

where $x_{i}=$ the dimensionless coded value of the variable $X_{i} ; X_{0}=$ the value of the $X_{i}$ at the centre point; and $\delta X=$ the step change [23].

The behavior of the system can be explained by the following quadratic equation. The responses were optimized by a second-order model.

$$
y=\beta_{0}+\sum_{i=1}^{k} \beta_{i} x_{i}+\sum_{i=1}^{k} \beta_{i i} x_{i}^{2}+\sum \sum_{i<j} \beta_{i j} x_{i} x_{j}+\varepsilon
$$


where $y$ is the predicted response, $\beta_{i}$ and $\beta_{i j}$ are the coefficients of the equation, $\beta_{0}$ is the intercept of the plane, $x_{i}$ and $x_{j}$ are coded levels of variables, and $\varepsilon$ is the error term. The optimal values were calculated by the software MINITAP using equation (5).

\section{Results and Discussion}

Screening of important factors for astaxanthin production by H.pluvialis

Fractional factorial design (FFD), $2_{I I I}^{6-3}$ design, was used to screen major induction factors of astaxanthin accumulation. For the statistical analysis, astaxanthin concentration per fresh weight was selected as the response. As shown in Table 4, effects were used to determine the relative strength of each factor and these coefficients were used to relate the responses with the factors. A higher value of relative strength corresponds with a greater effect on the response. Accordingly, light intensity and nitrate concentration were identified as the main factors.

Table 4. The effects and coefficients of variables in factional factorial design on astaxanthin production ( $g$ astaxanthin/g fresh cell weight) with statistical importance

\begin{tabular}{cccccc}
\hline Variables & Effect & Coef. & SE Coef. & $\boldsymbol{t}$-value & $\boldsymbol{p}$-level \\
\hline Constant & - & 6.2862 & 0.4401 & 14.28 & 0.000 \\
Light & 2.3309 & 1.1655 & 0.4401 & 2.65 & $0.014^{\mathrm{a}}$ \\
Intensity & & & & & \\
Nitrate & 1.5371 & 0.7685 & 0.4401 & 1.75 & $0.093^{*}$ \\
Phosphate & -0.4606 & -0.2303 & 0.4401 & -0.52 & 0.605 \\
Acetate & 0.8929 & 0.4465 & 0.4401 & 1.01 & 0.320 \\
Salt & 0.3348 & 0.1674 & 0.4401 & 0.38 & 0.707 \\
Temperature & 0.5971 & 0.2985 & 0.4401 & 0.68 & 0.504 \\
\hline
\end{tabular}

${ }^{\text {a }} p$-levels of coefficients are given as $* 90 \%$ by $t$-test.

Figure 1 is the normal probability plot of the effects. The normal probability plot provides an intuitive explanation of significant effects. The non-significant effects lie along the straight line representative for the normal distribution, whereas the significant effects that show large deviation are located far from the straight line. From this analysis, the important effects are found to be the main effects of $\mathrm{A}$ and $\mathrm{B}$, i.e., light intensity and nitrate concentration. The effectiveness of some single factors (phosphate, acetate $+\mathrm{pH}$, salt, temperature) was not significant for astaxanthin induction.

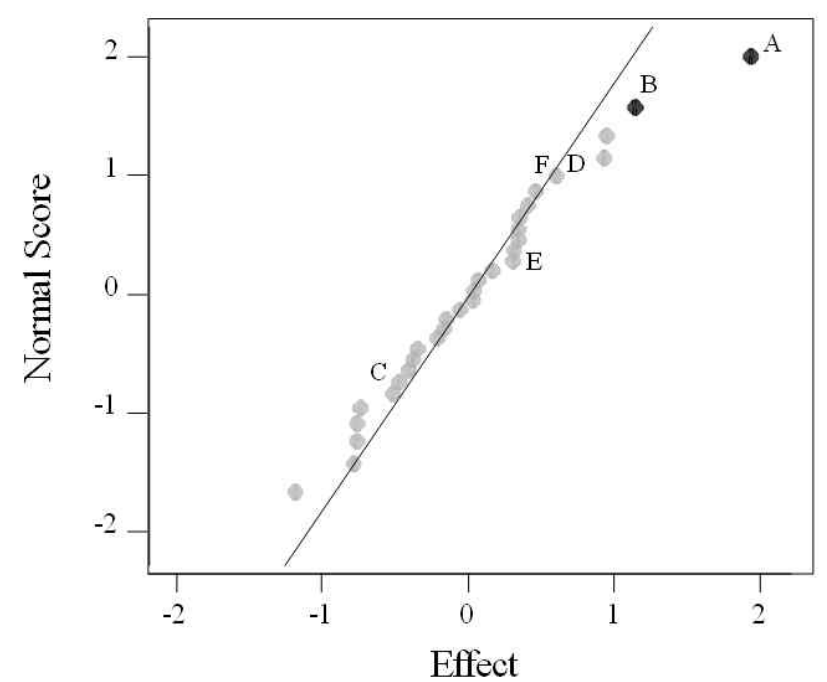

Figure 1. Normal probability plot of the effect.

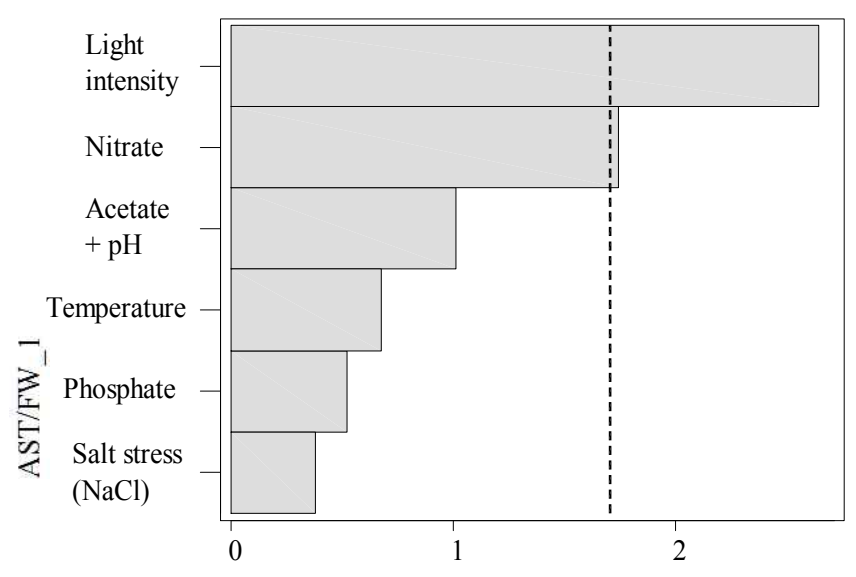

Figure 2. Pareto effects plot.

Figure 2 presents a Pareto chart. It is used to compare the relative magnitude and the statistical significance of the effects. The graph plots the effects in decreasing order of the absolute value of the standardized effects and a reference line is drawn on the chart. Any effect that extends past this reference line is significant. As can be seen in Figure 2, light intensity and nitrate concentration extend past this reference line, and as a result, these two factors were identified as being significant [5].

The main effects for astaxanthin production are plotted in Figure 3. The dashed line means the average of the response factor. If the solid line is 


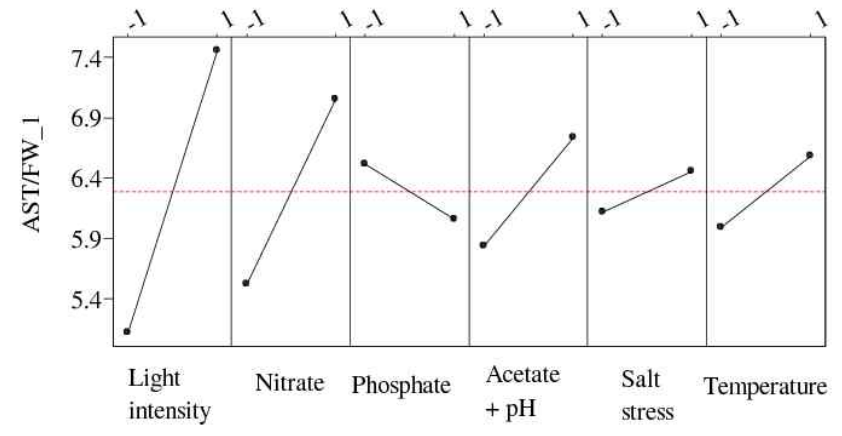

Figure 3. The effects of major factors identified in FFD (represented in arbitrary unit of astaxanthin concentration per fresh cell weight).

close to the dashed line, the variables do not affect the response factor. On the contrary, the main effect arises as distance between the solid line and the dashed line increases. These plots show that light intensity and nitrate concentration of culture media are identified as impact factors of astaxanthin accumulation, even though all six factors have an effect on astaxanthin accumulation. Figure 4 is an interaction plot. An interaction plot is used to determine if two factors interact in their effect on the response and to compare the relative strength of the effects. If the lines are not parallel to each other, there is an interaction present. Light intensity interacted with nitrate, acetate, and salt, whereas nitrate interacted with phosphate, acetate, and temperature.

A statistical approach for inducing factors was employed in a study of production of astaxanthin by Choi et al.[3]. Choi et al. claimed that a combination of nitrogen deficiency and acetate addition significantly increased astaxanthin content. However, in the present study, the interaction of nitrate and acetate was not identified as a main effect factor. The single factor of light intensity had a greater effect than interaction with factors.

The results of FFD experiments indicate that the amount of astaxanthin accumulation in Haematococcus cultures can be more enhanced by excessive irradiance and nitrate starvation than by the other factors tested.

Optimization of screened factors for astaxanthin production by H.pluvialis

In order to optimize astaxanthin production, a central

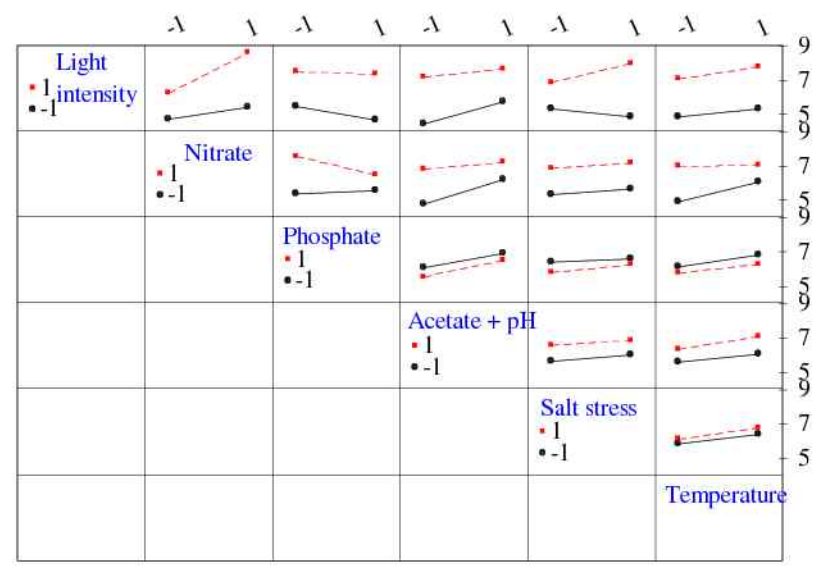

Figure 4. Interaction among major factors (represented in arbitrary unit of astaxanthin concentration per fresh cell weight).

composite design (CCD) was applied. Light intensity, nitrate, phosphate, and acetate were included as the variables for the CCD with five levels for each. Light intensity and nitrate were selected as effective factors from the FFD. Phosphate and acetate were included in CCD because they were known as induction factors for astaxanthin production $[1,4,10$, 14]. Central values of nitrate and phosphate were taken from the original concentration of MBBM while the acetate concentration was $0.2 \mathrm{~g} / \mathrm{L}$. The central value of the light intensity was taken as 540 $\mu \mathrm{E} /\left(\mathrm{m}^{2} \cdot \mathrm{s}\right)$. Final astaxanthin content $(\mathrm{mg} / \mathrm{g})$ was measured as the response.

Table 5 shows the regression models generated by the Response Surface Regression (MINITAB), which relates the astaxanthin content $(\mathrm{mg} / \mathrm{g})$ to the tested variables. The $p$-values determine which effects in the model are statistically significant. The significance level of each factor was determined using a $t$-test. This $p$-value was compared to the $a$-level $(a=0.05)$. If the $p$-value is less than or equal to $a$, then the effect is deemed significant. However, if the $p$-value is greater than $a$, the effect is not considered significant. A $p$-value of 0.000 for the light intensity and nitrate means the effects of light intensity and nitrate are significant (Table 5). Acetate was also found to be significant. In contrast, all the terms that contain phosphate concentration are not significant.

From the response surface plots (Figures 5-7), it can be seen that astaxanthin content increases with increasing light intensity, whereas the astaxanthin 
Table 5. The coefficients of variables in CCD on astaxanthin concentration per dry cell weight $(\mathrm{g} / \mathrm{g})$.

\begin{tabular}{c|cccc}
\hline Variables & Coef. & SE Coef. & $\boldsymbol{t}$-value & $\boldsymbol{p}$-level \\
\hline Constant & 0.020000 & 0.001201 & 16.648 & 0.000 \\
light & 0.005667 & 0.000601 & 9.434 & $0.000^{*}$ \\
nitrate & -0.003333 & 0.000601 & -5.549 & $0.000^{*}$ \\
phosphate & 0.000667 & 0.000601 & 1.110 & 0.287 \\
acetate & -0.001500 & 0.000601 & -2.497 & $0.027^{*}$ \\
light*light & -0.000917 & 0.000562 & -1.631 & 0.127 \\
nitrate*nitrate & -0.001667 & 0.000562 & -2.966 & $0.011^{*}$ \\
Phosphate*phosphate & -0.002167 & 0.000562 & -3.856 & $0.002^{*}$ \\
acetate*acetate & -0.001542 & 0.000562 & -2.744 & $0.017^{*}$ \\
light*nitrate & 0.000125 & 0.000736 & 0.170 & 0.868 \\
$\begin{array}{c}\text { light*phosphate } \\
\text { light*acetate }\end{array}$ & 0.000125 & 0.000736 & 0.170 & 0.868 \\
$\begin{array}{c}\text { nhtrate*phosphate } \\
\text { nitrate*acetate }\end{array}$ & -0.000000 & 0.000736 & 0.000 & 1.000 \\
\hline phospate*acetate & -0.0006500 & 0.000736 & -0.680 & 0.509 \\
\hline
\end{tabular}

*represents significant effect on astaxanthin concentration per dry cell weight $(p$-value $<0.05)$

content decreases as the nitrate concentration increases. Light intensity affects the astaxanthin content dramatically, especially when the nitrate concentration is low (near $0 \mathrm{~g} / \mathrm{L}$ ) as shown in Figure 5 (a). Furthermore, light intensity has a particularly significant effect when the phosphate concentration is about $0.3 \mathrm{~g} / \mathrm{L}$ and the acetate concentration is $0.1 \mathrm{~g} / \mathrm{L}$ (Figures 5 (b) and 6 (a)). The optimal concentration of nitrate is around 0 g/L (Figures 6 (b) and 7 (a)). Figure 7 (b) shows the optimal phosphate and acetate concentrations, i.e., $0.31 \mathrm{~g} / \mathrm{L}$ and $0.05 \mathrm{~g} / \mathrm{L}$, respectively. Through these plots, it is found that astaxanthin production increases as the light intensity increases and the nitrate concentration decreases.

As the regression models used in Table 5 are rather complicated, a stepwise regression analysis was used to simplify this model. Compared with the models shown in Table 5, equation (7) more clearly reflects the effects of the induction factors.

$$
\begin{aligned}
Y= & 0.0200+0.0057 X_{1}-0.0033 X_{2}-0.0015 X_{4} \\
& -0.0017 X_{2}^{2}-0.0021 X_{3}^{2}-0.0015 X_{4}^{2}
\end{aligned}
$$

By running the optimization program within the investigated experimental range, the following optimal values were obtained for attaining maximum astaxanthin content: $1040 \mu \mathrm{E} /\left(\mathrm{m}^{2} \cdot \mathrm{s}\right)$ light intensity, $0.04 \mathrm{~g} / \mathrm{L}$ nitrate, $0.31 \mathrm{~g} / \mathrm{L}$ phosphate, and $0.05 \mathrm{~g} / \mathrm{L}$ acetate.

Response surface methodology (RSM) has been applied in several similar studies to optimize inducing factors for production of astaxanthin. Harker et al. examined 3 factors, photon flux density, salt, and temperature [9]. The optimum light intensity and temperature for astaxanthin production could not be identified because the light also delivered excessive heat. Gong and Chen [8] applied a central compose design to statistically optimize the nutrients in the culture medium. As a result of FFD, light intensity interacted with nitrate and acetate. It supposed that the relationship between an environmental factor (light intensity) and nutrient (nitrate and acetate) affected the optimum conditions of astaxanthin production by the CCD. It's the reason why the results in this experiment were different with the previous studies for optimization of nutrients or environmental factors $[7,8,9,25,27]$.

In this study, two major aspects, environmental factors (such as temperature, light intensity, and $\mathrm{pH}$ ), and nutrient components, were considered to develop an optimal process for commercial production of astaxanthin. In the present study, these two aspects were also examined but at the same time. First, the important factor for inducing astaxanthin accumulation was screened by a fractional factorial design. Second, the screened factors were optimized by a central composite design. Thus, the best inducing conditions for production of high density astaxanthin were found. The use of these techniques proved useful in identifying the components that have significant effects on astaxanthin production. As a whole, the methodology of incorporating FFD and CCD is deemed to be very effective for the process of astaxanthin production. 
(a)

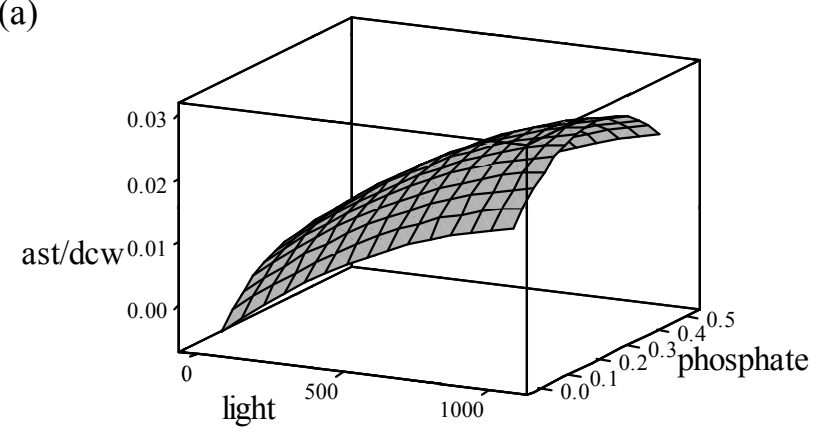

(b)

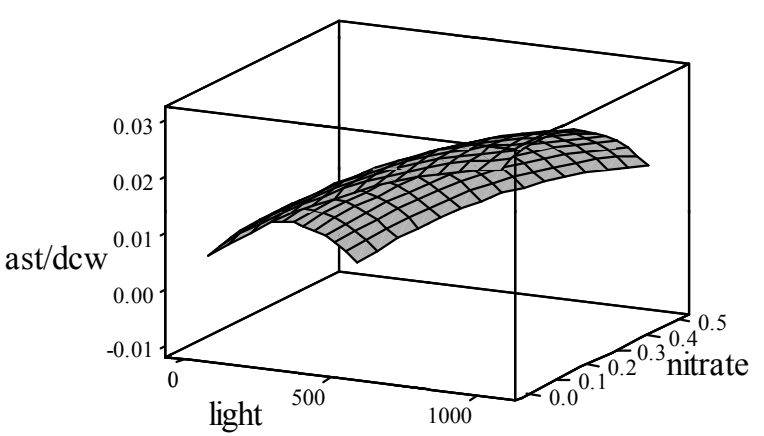

Figure 5. Response surface plot of astaxanthin content $(\mathrm{mg} / \mathrm{g})$ (a) light intensity $\left(\mu \mathrm{E} /\left(\mathrm{m}^{2} \cdot \mathrm{s}\right)\right)$ versus nitrate $(\mathrm{g} / \mathrm{L})$ with constant levels of concentrations of the phosphate, $0.25 \mathrm{~g} / \mathrm{L}$; acetate, $0.2 \mathrm{~g} / \mathrm{L}$, (b) light intensity $\left(\mu \mathrm{E} /\left(\mathrm{m}^{2} \cdot \mathrm{s}\right)\right)$ versus phosphate $(\mathrm{g} / \mathrm{L})$ with constant levels of concentrations of the nitrate, $0.246 \mathrm{~g} / \mathrm{L}$; acetate, $0.2 \mathrm{~g} / \mathrm{L}$.

(a)

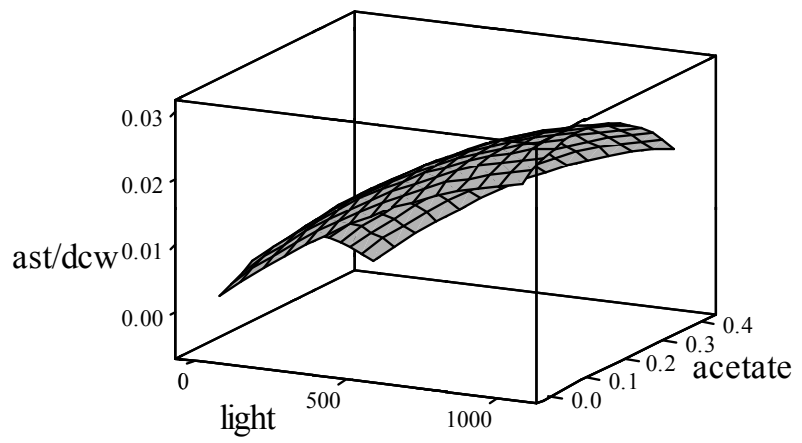

(b)

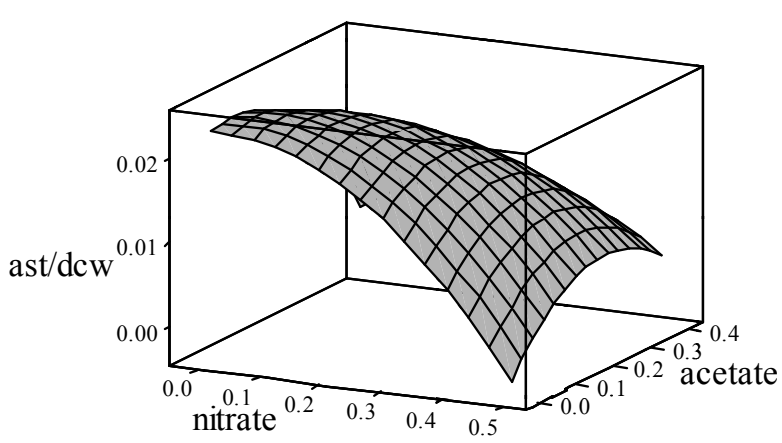

Figure 6. Response surface plot of astaxanthin content $(\mathrm{mg} / \mathrm{g})$ (a) light intensity $\left(\mu \mathrm{E} /\left(\mathrm{m}^{2} \cdot \mathrm{s}\right)\right)$ versus acetate $(\mathrm{g} / \mathrm{L})$ with constant levels of concentrations of the nitrate, $0.246 \mathrm{~g} / \mathrm{L}$; phosphate, $0.25 \mathrm{~g} / \mathrm{L}$, (b) nitrate $(\mathrm{g} / \mathrm{L})$ versus acetate $(\mathrm{g} / \mathrm{L})$ with constant levels of concentrations of the light intensity, $540 \mu \mathrm{E} /\left(\mathrm{m}^{2} \cdot \mathrm{s}\right)$; phosphate, $0.25 \mathrm{~g} / \mathrm{L}$.

(a)

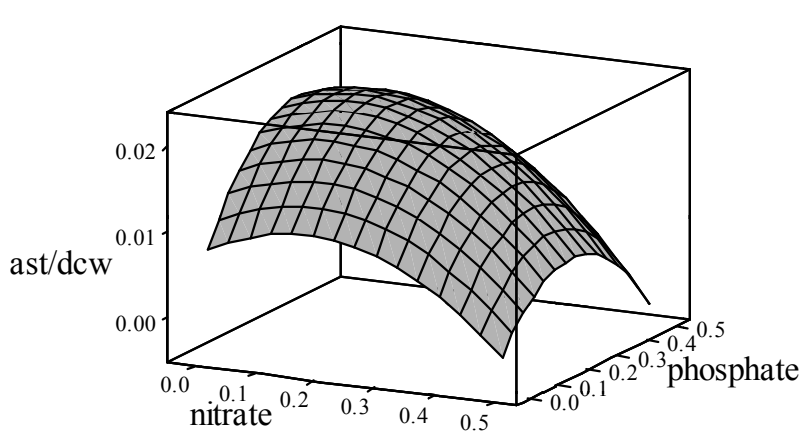

(b)

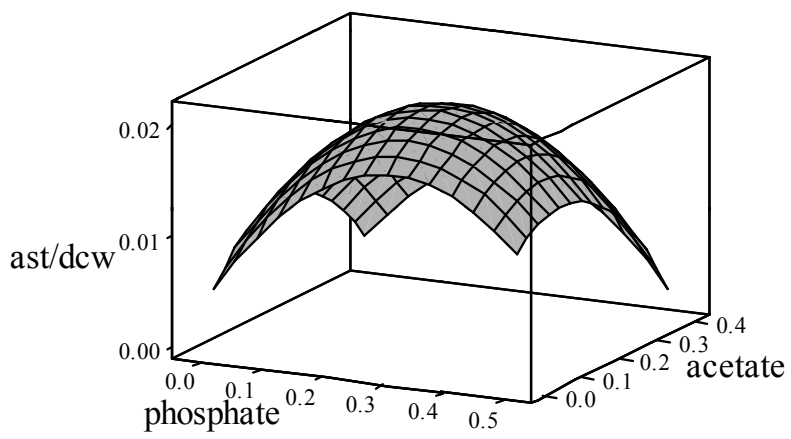

Figure 7. Response surface plot of astaxanthin content $(\mathrm{mg} / \mathrm{g})$ (a) nitrate $(\mathrm{g} / \mathrm{L})$ versus phosphate $(\mathrm{g} / \mathrm{L})$ with constant levels of concentrations of the light intensity, $540 \mu \mathrm{E} /\left(\mathrm{m}^{2} \cdot \mathrm{s}\right)$; acetate, $0.2 \mathrm{~g} / \mathrm{L}$, (b) phosphate $(\mathrm{g} / \mathrm{L})$ versus acetate $(\mathrm{g} / \mathrm{L})$ with constant levels of concentrations of the light intensity, $540 \mu \mathrm{E} /\left(\mathrm{m}^{2} \cdot \mathrm{s}\right)$; nitrate, $0.246 \mathrm{~g} / \mathrm{L}$. 


\section{Conclusion}

In developing an optimal process for commercial production of astaxanthin, two major aspects are usually considered with regard to improving the productivity: the high-density culture of vegetable cells and optimization of astaxanthin production. In this work, the optimization of astaxanthin production by $\mathrm{H}$. pluvialis through a factorial design and response surface methodology (FFD and CCD) was investigated in photoautotrophic batch cultivations. Using these two methods, the most influential factor on the accumulation of astaxanthin in cellular content could be identified. Six environmental factors were selected and their effects on astaxanthin accumulation were compared using a fractional factorial design. The experimental results indicate that the amount of astaxanthin accumulation in the cells can be enhanced by excessive irradiance and nitrate starvation. Excessive irradiance was the most important factor. From these results, a central composite design was constructed. The central composite design was then applied with four variables, light intensity, nitrate, phosphate, and acetate, at five levels each. The optimal conditions for attaining maximal astaxanthin production were found to be $1040 \mu \mathrm{E} /\left(\mathrm{m}^{2} \cdot \mathrm{s}\right)$ light intensity, $0.04 \mathrm{~g} / \mathrm{L}$ of nitrate, $0.31 \mathrm{~g} / \mathrm{L}$ of phosphate, and $0.05 \mathrm{~g} / \mathrm{L}$ acetate concentration. FFD and CCD were successfully used in the present study as a convenient and systematic approach to the realization of a design for inducing astaxanthin formation.

\section{Acknowledgements}

This study was supported by the National Research Foundation of Korea Grant funded by the Korean Government (MSIP) (NRF-2013M1A5A1055492). This research was also supported by a grant from Marine Biotechnology Program Funded by Ministry of Oceans and Fisheries, Korea.

\section{References}

1. Borowitzka, M. A., J. M. Huisman, and A. Osborn. 1991. Culture of astaxanthin-producing green alga Haematococcus pluvialis 1. Effects of nutrients on growth and cell type. J. Appl. Phycology 3, 295-304.

2. Choi, S.-L., I. S. Suh, and C.-G. Lee. 2003. Lumostatic operation of bubble colimn photobioreactors for Haematococcus pluvilis cultures using a specific light uptake rate as a contral parameter. Enzyme Microb. Technol. 33, 403-409.

3. Choi, Y. E., Y.-S. Yun, and J. M. Park. 2002. Evaluation of factors promotion astaxanthin production by a unicelluar green alga, Haematococcus pluvialis, with fractional factorial design. Biotechnol. Prog. 18, 1170-1175.

4. Cordero, B., A. Otero, M. Patino, B. O. Arredondo, and J. Fabregas. 1996. Astaxanthin production from the green alga Haematococcus pluvialis with different stress conditions. Biotech. Lett. 18, 213-218.

5. Ellekjar, M. R. and S. Bisgaard. 1998. The use of experimental design in the development of new products. IJQS 3, 254-274.

6. Fan, L., A. Vonshak, and S. Boussiba. 1994. Effect of temperature and irradiance on growth of Haematococcus pluvialis (Chlotophytceae). J. Phycol. 30, 829-833.

7. Gong, X. and F. Chen. 1997. Optimization of culture medium for growth of Haematococcus pluvialis. J. Appl. Phycol. 9,437-444.

8. Gong, X. and F. Chen. 1998. Influence of medium components on astaxanthin content and production of Haematococcus pluvialis. Process Biochem. 33, 385-391.

9. Harker, M., A. J. Tsavalos, and A. J. Young. 1995. Use of response surface methodology to optimise carotenogenesis in the microalga, Haematococcus pluvialis. J. Appl. Phycology 7, 399-406.

10. Harker, M., A. J. Tsavalos, and A. J. Young. 1996. Factors Reponsible for Astaxanthin Formation in the Chlorophyte Haematococcus pluvialis. Bioresource Technol. 55, 207-214.

11. Johnson, N. and F. C. Leone. 1977. Statistics and experimental design in enfineering and the physical sciences. Toronto, Canada: John Wiley \& Sons, Inc.

12. Kakizono, T., M. Kobayashi, and S. Nagai. 1992. Effect of carbon/nitrogen ratio on Encystment 
accompanied with Astaxanthin formation in a Green Alga, Haematococcus pluvialis. J. Ferment. Bioengng. 74, 403-405.

13. Kobayashi, M., T. Kakizono, N. Nishio, and S. Nagai. 1992. Effects of Light Intensity, Light Quality, and Illumination Cycle on Astaxanthin Formation in a Green Alga, Haematococcus pluvialis. J. Ferment. Bioengng 74, 61-63.

14. Kobayashi, M., T. Kakizono, and S. Nagai. 1993. Enhanced carotenoid biosynthesis by oxidative stress in acetate-induced Cyst Cells of a Green Unicellular Alga, Haematococcus pluvialis. Appl. Envir. Microbiol. 59, 867-873.

15. Lorenz, R. T. and G. R. Cysewski. 2000. Commercial potential for Haematococcus microalgae as a natural source fo astaxanthin. Tibtech 18, 160-167.

16. Lorenz, R. T. 2001. HPLC and spectrometric analysis of carotenoids from Haematococcus algae oleoresin. BioAstin/NatuRose ${ }^{T M}$ TechnicalBulletin 20, 1-9.

17. Margalith, P. Z. 1999. Production of ketocarotenoids by microalgae. Appl. Microbiol. Biotechnol. 51, 431-438.

18. Mason, R. L., R. F. Gunst, and J. L. Hess. 1989. Statistical design and anaysis of experiments with applications to engineering and science. Tornto, Canada: John Wiley \& Sons, Inc.

19. Montgomery, D. C. 1997. Design and analysis of experiments. United States of America: John Wiley \& Sons, Inc.

20. Orosa, M., E. Torres, P. Fidalgo, and L. Abalde. 2000. Production and analysis of secondary carotenoids in green algae. J. Appl. Phycol. 12, 553-556.

21. Orosa, M., J. F. Valero, C. Herrero, and J. Abalde. 2001. Comparision of accumulation of astaxanthin in Haematococcus pluvialis and oter green microalgae under $N$-starvation and high light conditions. Biotech. Lett. 23, 1079-1085.

22. Park, E. K. and C. K. Lee. 2001. Astaxnanthin production by Haematococcus pluvialis under various light intensities and wavelength. J. Microbiol. Biotechnol. 11, 1024-1030.
23. Pujari, V. and T. S. Chanadra. 2000. Statistical optimization of medium components for enhanced riboflavin production by UV-mutant of Eremothecium ashbyii. Process Biochem. 36, 31-37.

24. Ramirez, J., H. Gutierrez, and A. Gschaedler. 2001. Optimization of astaxanthin production by Phaffia rhodozyma through factorial design and response surface methodology. J. Biotechnol. 88, 259-268.

25. Sarada, R., U. Tripathi, and G. A. Ravishankar. 2002. Influence of stress on astaxanthin production in Haematococcus pluvialis grown under different culture conditions. Process Biochem. 37, 623-627.

26. Stein, J. R. 1973. Culture methods and growth measurements. Handbook of phycological methods. London, UK: Cambridge University Press. pp 13-14.

27. Tjahjono, A. E., Y. Hayama, T. Kakizono, and S. Nagai. 1994. Hyper-accumulation of astaxanthin in a green alga Haematococcus pluvialis at elevated temperatures. Biotechn. Lett. 16, 133-138.

28. Tripathi, U., R. Sarada, R. Rao, and G. A. Ravishanker. 1999. Production of astaxanthin in Haematococcus pluvialis cultured in various media. Bioresource Technol. 68, 197-199.

29. Yates, P. and R. W. Mee. 2000. Fractional factorial designs that restrict the number of treatment combinations for factor subsets. Qual. Reliab. Engng. Int. 16, 343-354.

30. Yuan, J. P. and F. Chen. 1999. Hydrolysis kinetics of astaxanthin esters and stability of astaxanthin of Haematococcus pluvialis during saponification. $J$. Agric. Food Chem. 47, 31-35.

31. Yuan, J. P. and F. Chen. 2000. Purification of trans-astaxanthin from a high-yielding astaxanthin ester-producing strian of the microalga Heamatococcus pluvialis. Food Chem. 68, 443-448.

32. Zhang, D. H., Y. K. Lee, M. L. Ng, and S. M. Phang. 1997. Composition and accumulation of secondary carotenoids in Chlorococcum sp. J. Appl. Phycol. 9, 147-155. 